Edited by Kiriakos Xenitidis and
Colin Campbell
Contents
- Brexit woes
- Paternalism $v$. autonomy
Attachment, benign paternalism and nuances in
autonomy
Measuring outcomes of mindfulness
interventions

\section{Brexit woes}

I feel I must take issue with the first paragraph, if nothing else, of the 'To the Editor's desk' column by Kamaldeep Bhui in the August 2016 edition of the journal. ${ }^{1}$ To begin with, I am surprised that 'shock waves of worry' among people fearing social division and financial insecurity have just arisen following the Brexit vote. It seems to me that social division and financial insecurity have been growing in this country for some years, and that divisions in wealth are now at a level not seen since the 19th century. All this has happened while we have been members of the European Union, and the European Union has done nothing to ameliorate it. In fact, in its susceptibility to lobbying by big business, Brussels may even have made the situation worse.

I am also surprised to read about 'better collective interventions to tackle health inequalities', as the European Union has been the problem rather than a solution for large swathes of the European population. It is well known that emergency financial bailouts to Southern Europe have had such stringent conditions attached to them that many people in Greece, Portugal and Spain are suffering from terrible poverty and their health has been declining markedly. Suicide rates have increased in Ireland, Spain, Portugal and Greece, and levels of mental health have declined. Alcoholism and drug addiction have also increased. Malaria has made a reappearance in Greece - a country where it has not been seen since the 1970s. All this should be blamed fairly and squarely upon the European Union.

As for 'greater trust and cooperation' being at the heart of the European project, one only has to listen to the vengeful and threatening comments coming from people in Brussels about making Brexit difficult to realise that they were not our true friends and could scarcely be trusted. I think it is about time we abandoned this starry-eyed idealism about the European Union and got real.

1 Bhui K. Brexit, social division and discrimination: impacts on mortality and mental illness? Br J Psychiatry 2016; 209: 181-2.

Simon Nicholson, Consultant Psychiatrist, North Devon District Hospital. Email: simon.nicholson1@nhs.net

doi: 10.1192/bjp.210.1.83

\section{Paternalism v. autonomy}

Lepping et al ${ }^{1}$ rightly point out that autonomy is only one of several important ethical values, which, in the patient-doctor relationship, needs to be weighed against other values such as beneficence and justice. However, they do not seem to be aware of the factors which reduce our autonomy and how limited it therefore is in the first place. These factors include manipulation (think of the Brexit campaign), oppressive socialisation, coercion (e.g. through legislation), overconformity (which in the medical context may mean uncritical acceptance by patients of the suggestions of paternalistic doctors), inner necessity (the strong feeling that we have to do what we want to do - Martin Luther's 'Here I stand. I can do no other') and luck (we often think we are responsible for outcomes which are simply lucky occurrences)., ${ }^{2,3}$ As a consequence, our autonomy is much more limited than we think it is. For this reason, we need to consider how best to increase our autonomy, and the autonomy of patients, so that it can at least compete with other important values.

\footnotetext{
1 Lepping P, Palmstierna T, Raveesh BN. Paternalism v. autonomy - are we barking up the wrong tree? Br J Psychiatry 2016; 209: 95-6.

2 Kahneman D. Thinking, Fast and Slow. Penguin, 2011.

3 Crichton P. Self-Realization and Inner Necessity. Kiener Press, 2013.
}

Paul Crichton, Consultant Psychiatrist, Ministry of Justice. Email: paulcrichton@ doctors.org.uk

doi: 10.1192/bjp.210.1.83a

\section{Attachment, benign paternalism and nuances in autonomy}

I would like to share a few thoughts on autonomy ${ }^{1}$ from the perspective of a child psychiatrist concerned with attachment theory. Autonomy from my developmental perspective concerns 'balanced dependency', a dependency on others which changes with age and state. When ill, our dependency needs change, and we manage them differently. The only truly 'autonomous' people can be expected to end up in high-security prisons for recidivists.

Attachment theory in current versions emphasises that it is not about 'bonds' but about strategies to handle danger and threat, which develop depending on the contingencies to our distress signals during our earliest years and the ways in which our affective disarray can become soothed: dis-ease gets eased.

Put rather simply, the Type A strategy has a variety of forms, but underlying them is a trend to aim for self-sufficiency and avoid conflict with those in positions of power. Their distress signals are often low-key or not displayed. They appreciate the medical style referred to as 'benign paternalism': the doctor is the accepted expert and they wish to follow the expert's advice. They can feel distinctly out of sorts and rejected if asked to decide between treatment options.

There is some evidence that the previous generation of US doctors also had a predilection for a Type A strategy. ${ }^{1}$ Whether this has changed today is unanswered. The doctors' strategies also feed into the dynamic between the different attachment strategies used by patients and understanding their symptom language and needs for varieties of paternalism. ${ }^{2}$

The Type $\mathrm{C}$ attachment favours prioritising their own viewpoint (currently the media portrayal of Donald Trump illustrates the strategy well). This can be expected to put the Type C strategists in conflict with doctors who tend to paternalistic approaches.

In order to resolve the issues in your editorial ${ }^{1}$ we need to elaborate our understanding of autonomy and how we develop different predilections for degrees of paternalistic medicine and doctors need to be aware of their own attachment strategies and how these interact with those of their patients. This is the core dilemma for improving medical communication, and, 